\title{
Intertidal migration and habitat use by subadult Dungeness crab Cancer magister in a NE Pacific estuary
}

\author{
Kirstin K. Holsman*, P. Sean McDonald, David A. Armstrong \\ School of Aquatic and Fishery Sciences, University of Washington, Box 355020, Seattle, Washington 98195, USA
}

\begin{abstract}
Tidal migrations are inherent in the life histories of numerous demersal predators, and both the indirect and direct effects of these forays are important to the structure and function of littoral communities. In coastal estuaries of the Northeastern Pacific, Dungeness crabs Cancer magister are abundant and compose a significant portion of estuarine biomass. The nursery role of complex littoral habitats for young-of-the-year (0+) C. magister is well documented, yet the ecology of subsequent age classes within coastal estuarine systems, and within littoral areas in particular, remains unclear. The goal of our study was to elucidate habitat use and migratory patterns of subadult C. magister (40 to $130 \mathrm{~mm}$ carapace width; $1+$ and $>1+$ yr classes) in littoral eelgrass Zostera marina, oyster Crassostrea gigas, and unstructured littoral habitats (ULH). We employed 3 sampling techniques (trapping, acoustic telemetry, and underwater video) designed to examine various aspects of migratory behavior within Willapa Bay, Washington, a representative coastal estuary. Baited trap surveys revealed that relative catches of subadult C. magister are 30 to $50 \%$ higher on ULH than eelgrass or oyster beds, and are negatively correlated with catches of another large cancrid crab, C. productus. Ultrasonic telemetry observations suggest that subadult $C$. magister making nighttime foraging incursions prefer ULH to other littoral habitats, and underwater video observations show that migrations are influenced by tidal rhythms since movements are correlated with the direction and velocity of current flow in adjacent channels. Our results dramatically alter the perception of C. magister as a predominantly sublittoral predator, and underscore the significance of littoral habitats as important foraging areas.
\end{abstract}

KEY WORDS: Cancer magister - Dungeness crab $\cdot$ Habitat $\cdot$ Preference $\cdot$ Intertidal $\cdot$ Foraging · Estuaries $\cdot$ Sublittoral

Resale or republication not permitted without written consent of the publisher

\section{INTRODUCTION}

Migrations occurring at various spatial and temporal scales are integral components in the life histories of many crabs. Large-scale movements are well documented and are often associated with ontogenetic shifts in resource use (e.g. Gonzalez Gurriaran et al. 2002, Moksnes 2002) and/or seasonal movements to wintering grounds (e.g. Naylor 1962, Stone \& O'Clair 2001) or reproductive habitats (e.g. Hooper 1986, Stone \& O'Clair 2001, Forward et al. 2003). However, many species also undertake more frequent, albeit less conspicuous, migrations with circadian and/or circatidal periodicities (Gibson 2003). Forays between refuge habitats and foraging areas allow crabs to exploit food resources while limiting exposure to predators (Robles et al. 1989) and abiotic stress (Vannini \& Ruwa 1994). For example, productive littoral habitats are inhospitable to many crab species at low tide but some migrate from deeper water into littoral flats during flooding tides to access abundant prey (e.g. Hamilton 1976, Dare \& Edwards 1981, Robles et al. 1989).

The direct and indirect effects of predation by migrating benthic predators have long intrigued ecologists 
and form the basis for many fundamental theories in marine ecology. For example, patterns in the vertical distribution of species in littoral areas largely result from the interplay between interspecific competition (Connell 1961, Dayton 1971), pressure from sublittoral predators that access littoral areas during flood tides and strongly influence lower tidal extent of a species' distribution and morphology (Connell 1970, Paine 1974), and physiological stresses that limit the upper tidal range of a species' distribution (Foster 1971, Bertness 1981). Crabs are often the most prominent predators visiting littoral areas during flood tides (especially in estuarine systems), and consequently several authors have concluded that predation by migrating crabs is a mechanism that both reduces littoral prey populations and structures littoral benthic communities (Boulding 1984, Gee et al. 1985, Yamada \& Boulding 1996).

The Dungeness crab Cancer magister is among the most conspicuous benthic predators in coastal waters of the NE Pacific. Throughout its range from Unalaska, Alaska, to Santa Barbara, California (Jensen 1995), the highest densities of $C$. magister occur in estuarine systems, which act as nurseries for young of the year $(0+$ age class) and subadult crabs (40 to $130 \mathrm{~mm}$ carapace width [CW], 1+ and >1+ age classes, Gunderson et al. 1990). Large, mobile subadult $C$. magister compose the majority of crab biomass and often range in density from 600 to $3000 \mathrm{crabs} \mathrm{ha}^{-1}$ in sublittoral channels during low tide (Rooper et al. 2002). Not surprisingly, predation by $C$. magister is often assumed to impact populations of littoral prey (Asson Batres 1986, Iribarne et al. 1995, Byers 2002). However, evidence to support this claim is largely anecdotal, and only one study to date has attempted to examine patterns of intertidal movement by subadult C. magister. Stevens et al. (1984) compared crab abundance at one sublittoral and one littoral (at the level of mean lower low water; MLLW) location in Grays Harbor, Washington. The authors found circumstantial evidence that some crabs moved into littoral areas at high tide (i.e. crabs were captured in littoral areas at high tide and were absent at low tide), but no inferences were made concerning the significance of these migrations. Conversely, Holsman et al. (2003) modeled the energetic demand of subadult $C$. magister and available prey reserves in Willapa Bay, Washington, and concluded that crabs are obligated to migrate since sublittoral prey resources are insufficient to support observed abundances of crabs concentrated in shallow channels at low tide. It is estimated that subadult $C$. magister may derive between 80 and $90 \%$ of their daily energetic requirements from littoral sources in many areas of the estuary (Holsman et al. 2003).

There is no paucity of data concerning intertidal migrations by crabs in general (e.g. Dare \& Edwards
1981, Abello et al. 1991, Chatterton \& Williams 1994), yet to date, no study has examined the relative movement of these transient species into a range of distinct littoral habitats. Inherent structural and biotic differences between habitats likely influence patterns of habitat utilization, and clear identification of patterns is essential in order to accurately address ecological questions regarding predator-prey dynamics. Understanding littoral habitat use is particularly crucial for managing this important economic resource. There is currently a marked disparity between ecological studies that focus on predation by Cancer magister as important in structuring littoral communities, and management perspectives of life history that regard it as a primarily sublittoral predator.

In the present study we attempt to discern the spatial and temporal patterns of intertidal movement and habitat use by subadult Cancer magister in a typical large NE Pacific estuary, Willapa Bay, Washington. The following studies were designed to investigate the relative occurrence of subadult crabs in discrete littoral habitats in order to elucidate patterns of movement and habitat use by subadult C. magister. In particular we ask the following questions: (1) Do subadult crabs regularly migrate into littoral habitats on flood tides, (2) are intertidal migrations correlated with tidal range or current velocity, (3) what is the magnitude and extent of crab migrations, and (4) does the relative abundance of crabs vary among areas of complex epibenthic structure ('on-bottom' oyster culture and eelgrass beds) and unstructured habitats (bare mud or sand flats)?

\section{MATERIALS AND METHODS}

Traditional trawling and visual estimation methods were considered unsuitable for this study because of the cryptic nature of Cancer magister, the turbidity of mixed estuarine water, and the difficulty of sampling in shallow, highly-structured habitats (i.e. dense eelgrass beds or on-bottom oyster culture) during flood tides (Gibson 2003). Instead we employed 3 sampling techniques: baited trap arrays (box traps), underwater video observations, and acoustic telemetry. Each method varied in scope and resolution and the combination of all 3 allowed us to resolve patterns in habitat use across spatio-temporal scales. Baited trap arrays provide only coarse information on the relative use of habitats, but allow for broad-scale interpretation across a system over multiple years. Conversely, underwater video observations are spatially and temporally limited in scope, yet yield high-resolution observations of intertidal migrations. Acoustic telemetry is intermediate between the other methods, and provides 
detailed information about selection and behavior across a range of habitats accessible to the individual crabs under study.

Study site. As a representative NE Pacific estuary, Willapa Bay, Washington (Fig. 1), has been the focus of numerous recent ecological studies (e.g. Armstrong et al. 2003, Rooper et al. 2003, Ruesink et al. 2003) and was chosen for our study because of the abundance of subadult crab resident within. Willapa Bay is a large bar-built estuary (31970 ha at mean high water) characterized by vast littoral flats. Semidiurnal tides that range up to $4 \mathrm{~m}$ drain over $50 \%$ of the shallow bay daily, exposing 17500 ha of tidelands at MLLW (Feldman et al. 2000). During ebb tides, water exits littoral areas through an extensive network of tidal tributaries and secondary side channels, which eventually drain into a deeper primary channel. In general, the abundance of many mobile species, including Cancer magister, is highest in secondary channels (Rooper et al. 2002) where gentle channel slopes and numerous tidal tributaries provide access during flood tides to a mosaic of highly productive littoral eelgrass Zostera marina beds and unstructured sand and mud habitats.

The estuary also supports substantial commercial aquaculture of Pacific oysters Crassostrea gigas, which have largely replaced the native oyster Ostreola con-

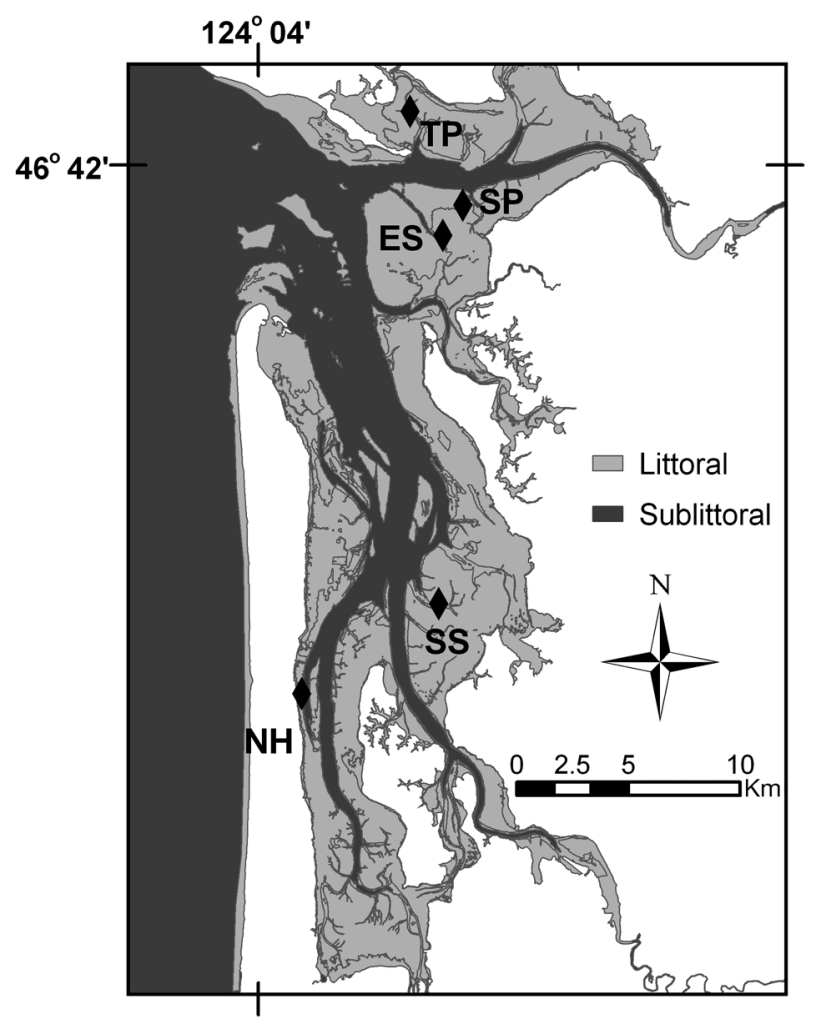

Fig. 1. Locations of sampling sites (diamonds) in Willapa Bay: Toke Point (TP), Stony Point (SP), Ellen Sands (ES), South Site (SS), and Nahcotta (NH) chaphila, and approximately $21 \%$ of tidelands are actively utilized for oyster production. Oysters are predominately cultured in 1 of 2 ways; cultch (inert oyster shell with newly settled oyster spat attached) may be strung on a line between $\sim 1 \mathrm{~m}$ tall stakes ('stake' or 'long line' culture), or it may be dispersed directly onto littoral flats ('on-bottom' culture). The structural complexity of on-bottom culture is unique in the system and ecologically important as refuge for myriad small invertebrates, including 0+ crabs (Fernandez et al. 1993, Eggleston \& Armstrong 1995). Some of the highest densities and biomass of a variety of species within the system occur in mature (2 to $3 \mathrm{yr}$ ) on-bottom oyster beds (K. K. Holsman unpubl. data).

Box-trap surveys. We conducted box-trap surveys at 4 locations across the bay in July 2002 and 5 locations in June 2004 in order to ascertain relative patterns of habitat use by subadult Cancer magister across the entire system. Locations were selected that had discrete patches of on-bottom Crassostrea gigas culture, Zostera marina beds, and unstructured littoral habitats (ULH) adjacent to secondary sublittoral channels. At each location, trap surveys were done on the 3 habitats simultaneously. Fifteen Fukui multi-species marine traps (model FT-100; $60 \times 45 \times 20 \mathrm{~cm} ; 12 \mathrm{~mm}$ mesh) were baited with $200 \mathrm{~g}$ of mackerel and set in standard arrays at each site with traps 50 m apart. In 2002 traps were immersed for $24 \mathrm{~h}$ at 4 locations (Fig. 1): Ellen Sands (ES), South Site (SS), Stony Point (SP), and Toke Point (TP). In 2004 soak time was limited to $12 \mathrm{~h}$ during nighttime high tides (when we observed the largest catches in our 2002 survey) and trapping occurred at 5 locations; ES, SS, SP, TP, and Nahcotta $(\mathrm{NH})$. Upon retrieval of the traps, all crabs were identified to species, sexed, assessed for limb damage, and their CW was measured to the nearest $0.1 \mathrm{~mm}$. Using the methods outlined by Zar (1999), traps were treated as replicates and differences in mean catch in each year were tested using a 2-way ANOVA with sampling location (ES, SS, SP, TP, and NH in 2004) and habitat type (oyster, eelgrass, and ULH) as factors. The analysis was followed by Tukey's HSD pair-wise comparisons. A similar analysis was done to determine differences in the CW of crabs captured in 2002 and 2004, except crabs were pooled within habitats at each location. In all analyses, data were transformed in order to meet model assumptions of normality and equality of variance (Zar 1999). Additionally, the curve estimation procedure (SPSS for Windows 9.0.0) was used to explore the relationship between catches of C. magister and C. productus.

Underwater video. All video observations took place between July and September near TP (Fig. 1), where the variety of littoral habitats found within Willapa Bay is well represented. Dare \& Edwards (1981) first 
employed underwater video to monitor intertidal migrations of Carcinus maenas in Europe, and a modified design was adopted in the present study to observe Cancer magister traveling between littoral and sublittoral areas. Fyke (funnel shaped) 'video gates' constructed of $13 \mathrm{~mm}$ wire or plastic mesh were placed in littoral habitats approximately $10 \mathrm{~m}$ from the edge of the sublittoral channel. Gates were constructed of $15 \mathrm{~m}$ long panels that were $0.5 \mathrm{~m}$ high. Their orientation created two $15 \mathrm{~m}$ catchment zones; one facing the channel and the other a mirror image facing the littoral flat. A black and white underwater camera equipped with infrared LEDs (Atlantis Underwater Video Systems, AUC-125C) was mounted in a box at the constriction between the 2 catchment zones and tethered to a video cassette recorder on a nearby support boat. We made continuous recordings of crab activity throughout the observation period, and the net frequency of crabs migrating between sublittoral and littoral areas per 10 min interval was calculated for all video observations in 2002 and 2003. In 2002 the CWs of crabs were estimated as individuals passed beneath the camera and over a $10 \mathrm{~cm}$ grid (10 $\mathrm{mm}$ resolution) located on the floor of the camera box. In 2002 the gates were deployed on oyster, eelgrass, and ULH simultaneously, and the movement of crabs was recorded from 11:00 h July 25 through 10:00 h July 26. Concurrent measurements of water temperature and salinity were also taken. In 2003, observations were made on a predominately unstructured habitat for 5 consecutive days (August 1 to 6 ) but due to equipment failure, only observations made during daylight hours were considered. In addition to temperature and salinity, current velocity and direction were monitored using an Aanderaa Doppler Current Sensor (DCS 3900).

The mean CW of crabs migrating during the 2002 video observations were calculated and differences in mean CW were tested by pooling crabs within habitats and applying an ANOVA with habitat type (oyster, eelgrass, and ULH) as a factor. The analysis was followed by Tukey's HSD pair-wise comparisons. In all analyses, data were transformed in order to meet model assumptions of normality and equality of variance (Zar 1999). To examine whether migrations were correlated with water velocity, the bivariate correlation procedure (SPSS for Windows 9.0.0) was used to calculate Pearson's correlation coefficient for the net frequency of Cancer magister migrating between littoral and sublittoral areas per $10 \mathrm{~min}$ interval and the velocity of water movement $\left(\mathrm{cm} \mathrm{s}^{-1}\right)$ during ebb and flood tides in 2003.

Manual acoustic telemetry. Ultrasonic telemetry has been used successfully to observe the movement patterns of various crab species (e.g. Wolcott 1995, Freire \& Gonzalez Gurriaran 1998) and provides a method for observing in situ activity of subadult Cancer magister without dramatically altering crab behavior. Spatial and temporal patterns in movement among sublittoral and littoral microhabitats were recorded and the resulting observations were combined with habitat information to examine patterns of habitat selection. Telemetric observations commenced during the evening of August 17, 2002, when 13 male and female crabs measuring 90 to $110 \mathrm{~mm} \mathrm{CW}$ were collected using baited box traps. Each crab was fitted with a uniquely coded $1.5 \mathrm{~g}$ sonotronics ${ }^{\circledR}$ acoustic tag. The tags were placed within a piece of surgical tubing and attached to the carapace of the crab using cyanoacrylate adhesive. Total time of tagging did not exceed $30 \mathrm{~min}$, and all 13 individuals were released simultaneously. A directional hydrophone was used to manually locate each $\mathrm{crab}$, and its geographic position was determined with a handheld global positioning system (GPS; Garmin Map76 ${ }^{\circledR}$ ).

Sequential observations complicate analysis of habitat use in telemetric studies, especially when subsequent positions are incorrectly treated as independent observations (Swihart \& Slade 1985). In order to alleviate problems of serial correlation of observations, many authors have suggested separating observations of an individual's position by sufficient time for the individual to utilize all potential habitats within their home range (e.g. Arthur et al. 1996). Since Cancer magister are rarely observed in littoral habitats at low tide and accordingly must return to sublittoral channels during ebb tides, we determined that separating observations by tidal period $(\sim 6 \mathrm{~h})$ would give adequate time for crabs to move to any of the surrounding habitats and thus reduce the potential for serial correlation. Therefore, positions were recorded for all individuals once per tidal maximum or minimum (4 times daily) for $7 \mathrm{~d}$, and then once per maximum high- and minimum low-tide ( 2 times daily) for $6 \mathrm{~d}$. At this point crabs had emigrated from the study area or the tag batteries had expired.

Geographic habitat information was collected with a handheld GPS by tracing the perimeter of major habitat features, including unstructured habitats, marshes composed of Spartina alterniflora, eelgrass beds, sublittoral channels, and on-bottom and stake oyster culture areas. Habitat perimeters were compiled within a geographic information system (GIS) using ESRI ArcView $3.2^{\circledR}$ software. The positions of individual crabs were overlaid on the habitat GIS layer and queries were conducted to determine temporal and spatial patterns of crab movement. The animal movement extension for ArcView 3.2 ${ }^{\circledR}$ (Hooge \& Eichenlaub 1997) was used to calculate 95 ('range') and 50\% ('kernel') distribution polygons for all crabs at each of the 4 tides. The net distance between 2 consecutive points was calculated for each observation ('path 
length') and a natural log transformation was used to meet model assumptions of normality and equality of variance. Transformed data were then compared with an ANOVA (Zar 1999) to determine if mean path lengths varied between daytime and nighttime high and low tides. Path length was assumed to be the linear difference between points and, although additional movement may have occurred, we did not record such activity in order to reduce serial correlation of observations.

Habitat selectivity is often determined by computing the ratio of habitat use to availability (Manly et al. 1993), or by using rank methods to compare use to availability (Aebischer et al. 1993). However, these methods are dependent on accurate estimation of available habitat and assume that availability is constant and unchanging. Habitat availability is often difficult to evaluate, and is particularly difficult to determine for migrating Cancer magister since tidal range may restrict or expand access to various littoral areas thus constantly changing the metric of habitat availability. Therefore, to assess habitat selection by subadult C. magister, and to resolve whether particular habitats were preferred or avoided, we employed methods outlined by Arthur et al. (1996) to calculate habitat selectivity when availability changes. Overall habitat selection indices $\left(\hat{b}_{k}\right)$ were calculated for each individual crab based on the following equations (modified from Arthur et al. 1996):

$$
\hat{b}_{k}=\frac{\sum_{t=1}^{N} O_{t k}}{\sum_{t=1}^{N} \frac{A_{t k}}{\sum_{j=1}^{H} A_{t j} \hat{b}_{j}}}
$$

where for each individual $\hat{b}_{k}$ is the estimated selection index for a particular habitat $k$ from the set $j=1 \ldots H$, and $H$ is the total number of habitats. $N$ is the number of tides on which the individual was located, $O_{t k}$ is either 0 or 1 and indicates the use of habitat $k$ during tide $t$, and $A_{t k}$ is the proportional availability (i.e. area) of habitat $k$ on tide $t . A_{t j}$ is the total availability for the set of all habitats (i.e. total area). Initially the values for $\hat{b}_{j}$ were set to $1 / H$ and used to solve Eq. (1) for $\hat{b}_{k i}$ values for $\hat{b}_{j}^{\prime}$ were then calculated through numerical iteration such that:

$$
\hat{b}_{j}^{\prime}=\frac{\hat{b}_{k}}{\sum \hat{b}_{k}}
$$

until $\sum \hat{b}_{k}=1$ and $\hat{b}_{j}^{\prime}$ for each habitat.

In this study the proportional availability of a habitat $\left(A_{t k}\right)$ was calculated as the area of habitat $k$ divided by the sum of the area of all available habitats within the range of the individual during a given tide $t$. Since the range of an individual crab was constantly changing, we defined total available habitat separately for each crab location as a circle centered on the crab's previous location (See Fig. 2 in Arthur et al. 1996). The radius of the circle was set to $370 \mathrm{~m}$, which was the maximum distance a crab was likely to move in a single tide; only 2 crabs moved further than $370 \mathrm{~m}$ on a few occasions $(0.4 \%)$. In some instances, crab locations could not be obtained for 1 or 2 consecutive tides and so the radius of the circle was set to 640.5 and $875 \mathrm{~m}$, respectively. These distances represented the maximum distance a crab was observed moving when 1 or 2 previous tidal locations were missed, and encompassed $100 \%$ of the crab positions in these cases. The selection indices were determined for each individual crab for daytime and nighttime high-tide positions, and habitat preference was indicated by indices greater than the expected index value if habitat use was random $(1 / \mathrm{H}$, Arthur et al. 1996); this value was 0.2 in the present study.

\section{RESULTS}

\section{Box-trap surveys}

The mean number of Cancer magister caught per trap in both the 2002 (24 h) and 2004 (12 h) box trap surveys varied significantly among littoral oyster, eelgrass, and ULH habitats $\left(F_{2,142}=60.4, \mathrm{p}<0.001\right.$ and $F_{2,206}=44.1, \mathrm{p}<0.001$, respectively), with highest catches occurring in ULH and lowest catches in oyster habitats (Fig. 2). The total catch from traps placed on ULH composed $48 \%$ of all C. magister caught in the 2002 trapping survey (6424 crabs total) and $58 \%$ of all crabs caught in 2004 (5002 crabs total). Mean catch of C. magister also varied significantly between locations in both $2002\left(F_{3,142}=66.2, \mathrm{p}<0.001\right)$ and $2004\left(F_{4,206}=\right.$ 9.2, $\mathrm{p}<0.001)$, and was highest at TP and SS locations (Fig. 3). The combined catches from these locations composed 77 and $52 \%$ of all crabs captured in 2002 and 2004, respectively.

Baited traps predominately captured subadult Cancer magister $(\geq 1+\mathrm{yr})$ with $\mathrm{CW}$ ranging from 50 to $165 \mathrm{~mm}$. In 2002 and 2004 the mean size of crabs varied slightly across the bay $\left(F_{3,6362}=239.8, \mathrm{p}<0.001\right.$ and $F_{4,1653}=134.9, \mathrm{p}<0.001$, respectively) with the smallest crabs found farthest from the mouth and the largest crabs found in the northern part of the bay. The mean size of crabs caught in 2002 also varied significantly among habitats $\left(F_{2,6362}=13.1, \mathrm{p}<0.001\right)$, with the largest crabs caught in oyster beds and the smallest caught in eelgrass and unstructured habitats (82.4 \pm $0.5,78.6 \pm 0.4$, and $77.0 \pm 0.3 \mathrm{~mm} \mathrm{CW}$, respectively). However, in the 2004 trapping survey CW did not differ significantly among habitats $\left(F_{2,1653}=1.7, \mathrm{p}=0.175\right)$. 


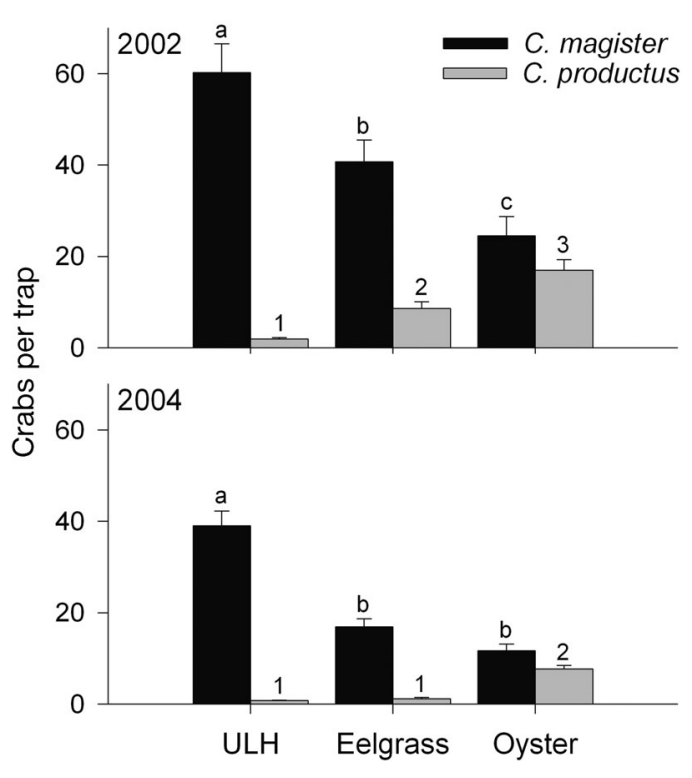

Fig. 2. Cancer magister and C. productus. Mean (+1 SE) number of crabs captured in baited traps placed in eelgrass, oyster, and unstructured littoral habitats (ULH). Traps were immersed for $24 \mathrm{~h}$ during the 2002 survey, and $12 \mathrm{~h}$ (nighttime) during the 2004 survey. Habitat types not sharing a common letter (for C. magister) or number (for C. productus) differed significantly $(\mathrm{p}<0.05)$ according to Tukey's HSD pair-wise comparison tests

Cancer productus was also abundant in the 2002 and 2004 box-trap surveys. Mean catches of C. productus varied significantly among locations, with the largest average catches in 2002 and 2004 at ES and SP (Fig. 3) in the northern part of the estuary $\left(F_{3,134}=121.9, \mathrm{p}<\right.$ 0.001 , and $F_{4,206}=65.3, \mathrm{p}<0.001$, respectively). Mean catches of $C$. productus also varied significantly among habitats in $2002\left(F_{2,134}=48.7, \mathrm{p}<0.001\right)$ and $2004\left(F_{2,206}\right.$ $=223.2, \mathrm{p}<0.001)$, with the highest catches in oyster and the lowest catches in ULH (Fig. 2). Catches of $C$. magister were negatively correlated with catches of $C$. productus in baited traps (Pearson's $\mathrm{r}=-0.273, \mathrm{p}=$ 0.003), and the relationship was most pronounced at SP and ES locations where on-bottom oyster culture was $3 \mathrm{yr}$ old and percent shell cover was greater than at other locations. The average size of $C$. productus caught in baited traps did not vary significantly among habitats in $2002\left(F_{2,1376}=1.6, \mathrm{p}=0.21\right.$ and $2004\left(F_{2,521}=2.5, \mathrm{p}=\right.$ $0.02)$, or locations in $2002\left(F_{3,1376}=1.4, \mathrm{p}=0.24\right)$. In contrast, the mean size of $C$. productus captured in baited traps in 2004 varied significantly across the bay $\left(F_{4,521}=\right.$ $20.0, p<0.001$ ), with the largest crabs captured in the northern part of the system. Approximately $58 \%$ of all C. magister and C. productus crabs caught in baited traps in 2002 were males, and for both species males were significantly larger than females $\left(F_{1,6362}=193.5\right.$, $\mathrm{p}<0.001$ and $F_{1,1376}=358.6, \mathrm{p}<0.001$, respectively)

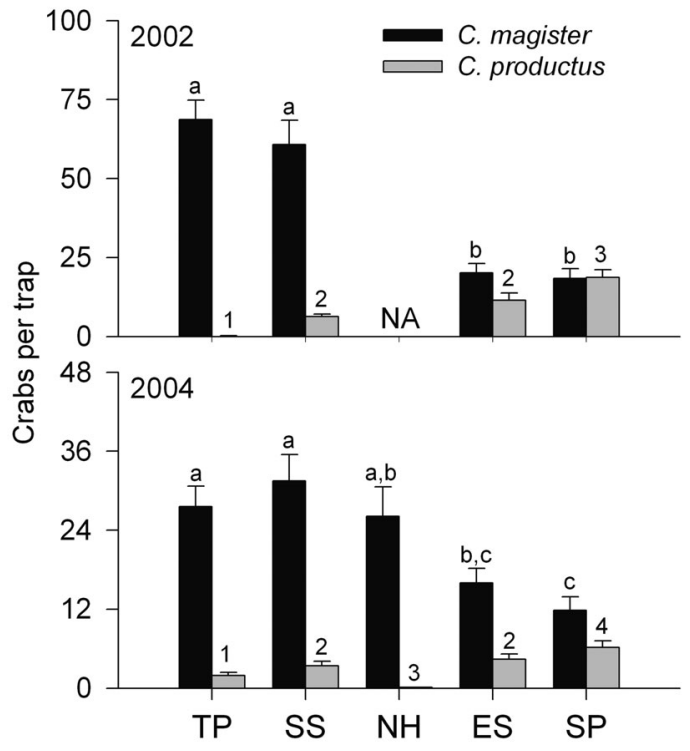

Fig. 3. Cancer magister and C. productus. Mean (+1 SE) number of crabs captured in baited traps at each sampling site in Willapa Bay, Washington: Toke Point (TP), Stony Point (SP), Ellen Sands (ES), South Site (SS), and Nahcotta (NH). Traps were immersed for $24 \mathrm{~h}$ during the 2002 survey, and $12 \mathrm{~h}$ (nighttime) during the 2004 survey. Sampling sites not sharing a common letter (for $C$. magister) or number (for $C$. productus) differed significantly $(\mathrm{p}<0.05)$ according to Tukey's HSD pair-wise comparison tests. NA: not applicable

\section{Underwater video}

The 2002 video observations showed marked temporal patterns in the magnitude of tidal migrations of Cancer magister into and out of all 3 habitats. In total, over 1300 C. magister migrated through video gates between sublittoral and littoral areas during the $24 \mathrm{~h} \mathrm{ob-}$ servation period, despite a missing interval due to equipment failure (21:00 to 05:00 $\mathrm{h}$ on the eelgrass site, see Fig. 4). During the period that all 3 cameras were recording movements (11:00 to 09:00 pm), relatively more crabs migrated into the ULH site than the eelgrass ( $66 \%$ of the ULH value) or on-bottom oyster sites (50\% of the ULH value). Similarly, migrations out of the ULH site during the ebb tide were nearly twice as large as migrations out of the eelgrass and oyster sites combined. Significantly larger crabs moved into and out of the oyster site $\left(F_{2,1305}=4.8, \mathrm{p}=0.009\right)$ than migrated through the eelgrass and unstructured sites $(83.8 \pm 1.8$, $77.3 \pm 0.7$, and $79.1 \pm 0.9 \mathrm{~mm} \mathrm{CW}$, respectively).

Video observations in 2002 and 2003 revealed that subadult Cancer magister move in accord with tidal periodicity (Figs. 4 \& 5, respectively). Peaks in migration between littoral and sublittoral areas occurred during maximum exchanges when current velocity was highest, often just prior to tidal maxima or minima 


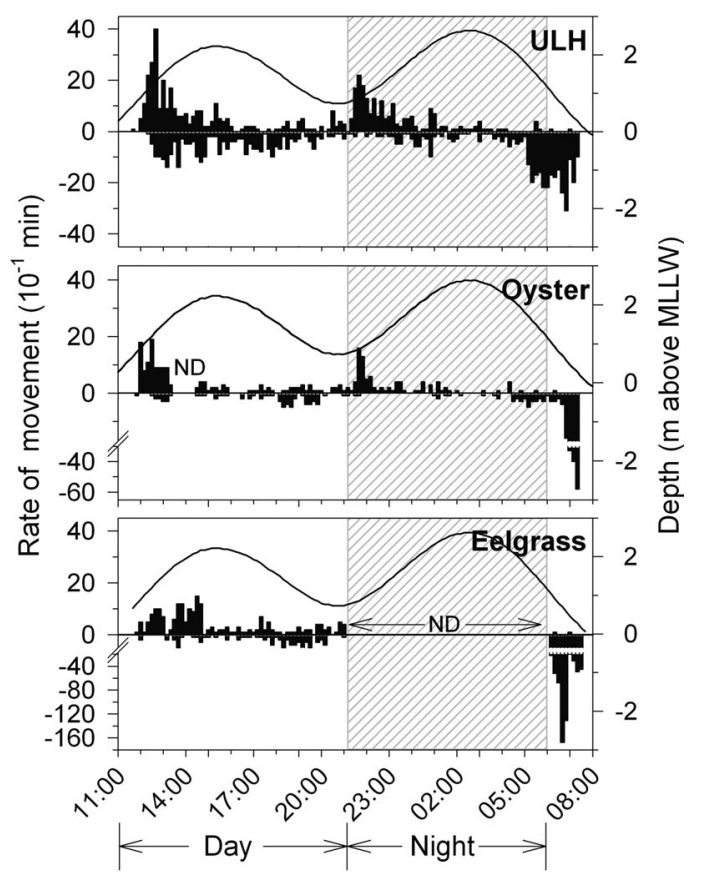

Fig. 4. Cancer magister. Underwater video observations from 2002 of crabs migrating between sublittoral channels and littoral habitats: eelgrass, oyster, and unstructured littoral habitats (ULH). Positive and negative values represent the number of crabs observed moving into and out of littoral habitats, respectively. The solid line shows tidal changes in water depth $(\mathrm{m})$ relative to mean lower low water (MLLW). Diagonal shading shows periods of darkness, and 'ND' indicates periods when the camera was obstructed and observations could not be made

(Fig. 6). In 2003 the magnitude and direction of crab migrations was significantly related to water current speed and direction on both flood $\left(\mathrm{r}^{2}=0.232, \mathrm{p}=0.004\right)$ and ebb tides $\left(r^{2}=0.224, p=0.004\right)$. While crabs moved into littoral flats during daytime and nighttime flood tides, emigration out of littoral areas was most pronounced during the morning ebb following a nighttime high tide (Figs. 4 \& 5). The magnitude of this migration decreased over the observation period as the magnitude of tidal exchanges diminished, and the smallest ebb migration was observed on August 5 when the tide no longer dropped below 0 m MLLW (Fig. 5).

\section{Manual ultrasonic telemetry}

Telemetric observations of subadult Cancer magister movement revealed that subadult crabs exhibit diurnal and tidal patterns in habitat use and movement. Male and female crabs showed similar patterns of movement and were generally more active at night, particularly during high tides, as indicated by the differences in average home-range size and maximum distances traveled

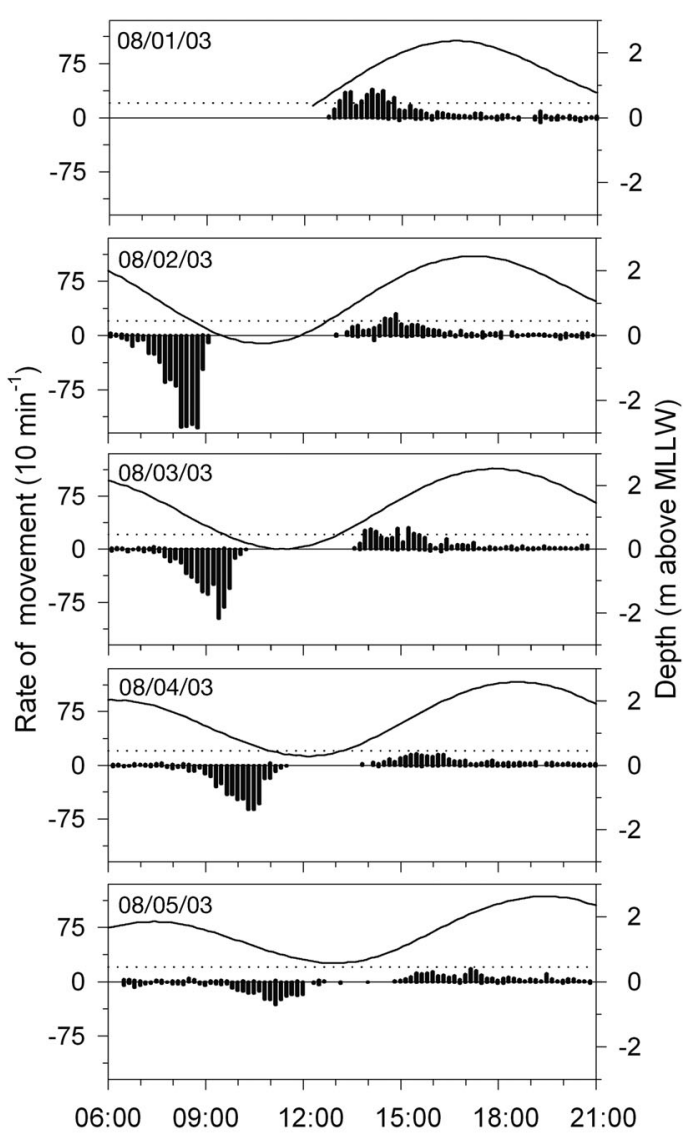

Fig. 5. Cancer magister. Daytime underwater video observations of crabs migrating between sublittoral channels and an unstructured littoral habitat (ULH) during a continuous 5 d observation period in 2003. Positive and negative values represent the number of crabs observed moving into and out of the littoral habitat, respectively. The solid line expresses tidal changes in water depth $(\mathrm{m})$ relative to mean lower low water (MLLW); the horizontal dotted line indicates the approximate depth at which the camera is exposed. Dates in top left corner given as mm/dd/yy; times on $x$-axes are given in $24 \mathrm{~h}$ clock format

during daytime high $(\mathrm{DH})$ and nighttime high $(\mathrm{NH})$ tides (Fig. 7, Table 1). In most measures of activity (home range, path length, and rate of movement), crabs were 2 - to 3 -fold more active during night than day, irrespective of tidal stage (Fig. 7, Table 1). During NH tides crabs expanded their ranges to include portions of the littoral flats (Fig. 7), and in a few cases, individuals repeatedly migrated more than $1.2 \mathrm{~km}$ round-trip (Fig. 8). Crabs moved significantly further during $\mathrm{NH}$ tides than $\mathrm{DH}$ tides $\left(F_{3,135}=12.6, \mathrm{p}<0.001\right)$.

More than half $(65 \% \pm 0.26)$ of all positions occurred in littoral habitats during $\mathrm{NH}$ tides (Fig. 9). Cancer magister generally remained in sublittoral areas during daytime tides (DH and DL), and at nighttime low (NL) tides were usually in deeper channels $(>2 \mathrm{~m})$, although some individuals occasionally moved into 


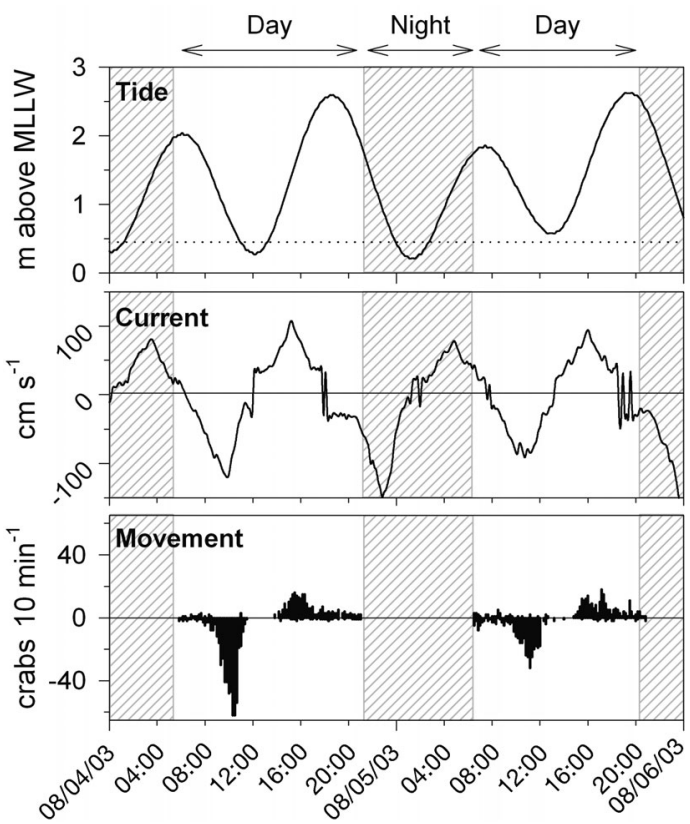

Fig. 6. Cancer magister. Tidal patterns in depth $(\mathrm{m})$ relative to mean lower low water (MLLW), current $\left(\mathrm{cm} \mathrm{s}^{-1}\right)$, and frequency of migrating crabs over a $2 \mathrm{~d}$ period in 2003 ; the horizontal dotted lie indicates the approximate depth of camera exposure. Diagonal shading indicates periods of darkness when video quality was low and the frequency of crab movement could not be measured accurately. $x$-axes are given as times in $24 \mathrm{~h}$ clock format, and dates given as mm/dd/yy

Table 1. Cancer magister. Path lengths (PL) or distance traveled $\mathrm{h}^{-1}$ (rate) by crabs during nighttime high (NH) and daytime high (DH) tides. Note that values for path length and rate reflect average movement preceding or following a given tidal period

\begin{tabular}{|c|c|c|c|c|}
\hline \multirow[b]{2}{*}{ Tide } & \multicolumn{2}{|c|}{ PL (m) } & \multicolumn{2}{|c|}{ Rate $\left(\mathrm{m} \mathrm{h}^{-1}\right)$} \\
\hline & Mean $( \pm \mathrm{SE})$ & Max & Mean $( \pm \mathrm{SE})$ & Max \\
\hline $\mathrm{NH}$ & $225.4(29.8)$ & 882.8 & $34.2(4.3)$ & 124.3 \\
\hline $\mathrm{DH}$ & 85.3 (11.5) & 417.5 & $15.4(2.2)$ & 92.1 \\
\hline
\end{tabular}

sublittoral eelgrass beds (Fig. $7 \mathrm{a}, \mathrm{c}$ ). Analysis of habitat selection revealed that selection indices $\left(\hat{b}_{k}\right)$ were greater for sublittoral channels than other habitats during DH tides. However, selection indices during $\mathrm{NH}$ tides were greater for sublittoral channels and ULH than for the other remaining habitats (Fig. 10). Additionally, the values for sublittoral habitats and ULH were greater than 0.2 , suggesting that subadult crabs selected these habitats during NH tides (Fig. 10).

\section{DISCUSSION}

A variety of brachyuran crabs undertake intertidal migrations at some point in their life history, including Callinectes sapidus (Hamilton 1976), Cancer productus (Robles et al. 1989), C. novaezelandiae (Chatterton \& Williams 1994), Carcinus maenas (Dare \&
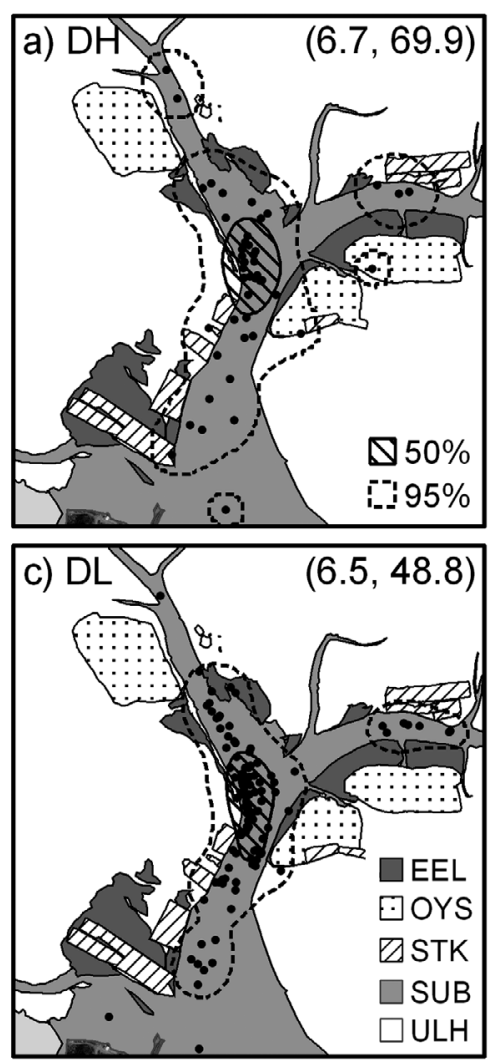
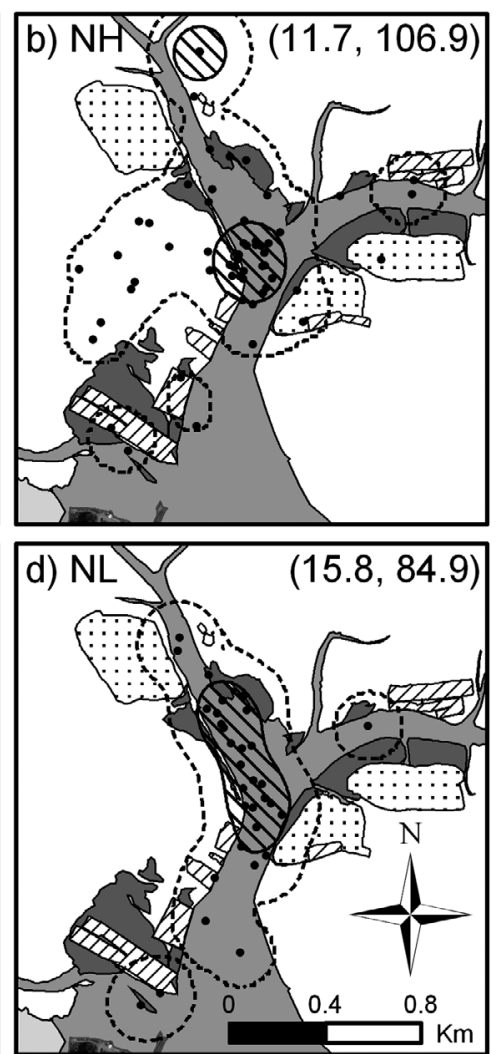

Edwards 1981, Hunter \& Naylor 1993), and Liocarcinus holsatus (Abello et al. 1991). The results of the present study suggest that subadult Cancer magister regularly migrate into littoral habitats as well, particularly during nighttime high $(\mathrm{NH})$ tides. These highly directed migrations are often extensive, with some individuals moving up to $600 \mathrm{~m}$ into littoral flats (1.2 km round-trip) within a single tide. Regular intertidal migrations to preferred unstructured littoral habitats (ULH) appear to be an integral component in the life-history of subadult C. magister, a finding

Fig. 7. Cancer magister. Locations of tagged crabs (filled circles) during the 2 wk 2002 telemetry study at Toke Point in Willapa Bay, Washington, grouped by tidal period: daytime high tides $(\mathrm{DH})$, nighttime high tides (NH), daytime low tides (DL), and nighttime low tides (NL). The $95 \%$ habitat-use polygon (dotted outline) indicates the home range of crab movement, and $50 \%$ (diagonal shading) polygon represents their home kernel. Values in parentheses represent the area (ha) of the 50 and $95 \%$ habitat-use polygons, respectively. EEL: eelgrass bed, OYS: on-bottom oyster culture, STK: stake oyster culture, SUB: sublittoral, ULH: unstructured littoral habitat 


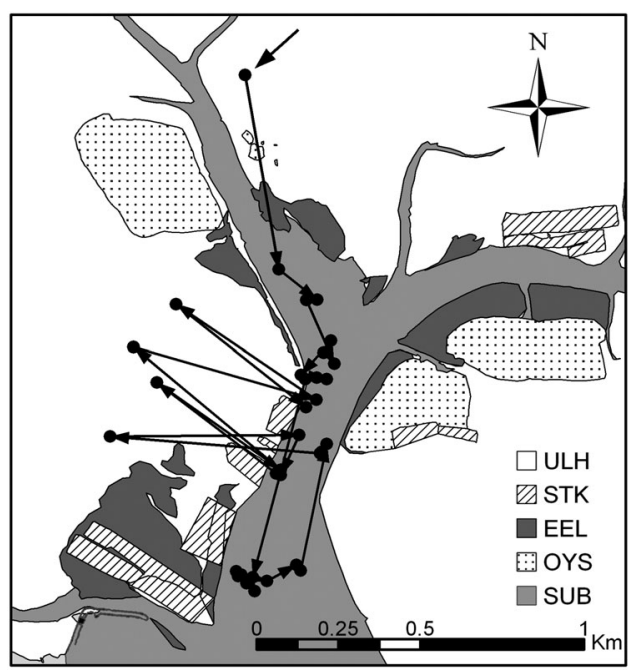

Fig. 8. Cancer magister. Daily movement path of a single crab during the 2 wk (August 17 to August 29) 2002 telemetry study at Toke Point in Willapa Bay, Washington. Each point represents the location of the crab determined from daily observations. Extensive littoral migrations often occurred during nighttime high tides and frequently exceeded $1 \mathrm{~km}$ round-trip. Arrows indicate the location where the crab was captured, tagged, and released. EEL: eelgrass bed, OYS: on-bottom oyster culture, STK: stake oyster culture, SUB: sublittoral, ULH: unstructured littoral habitat

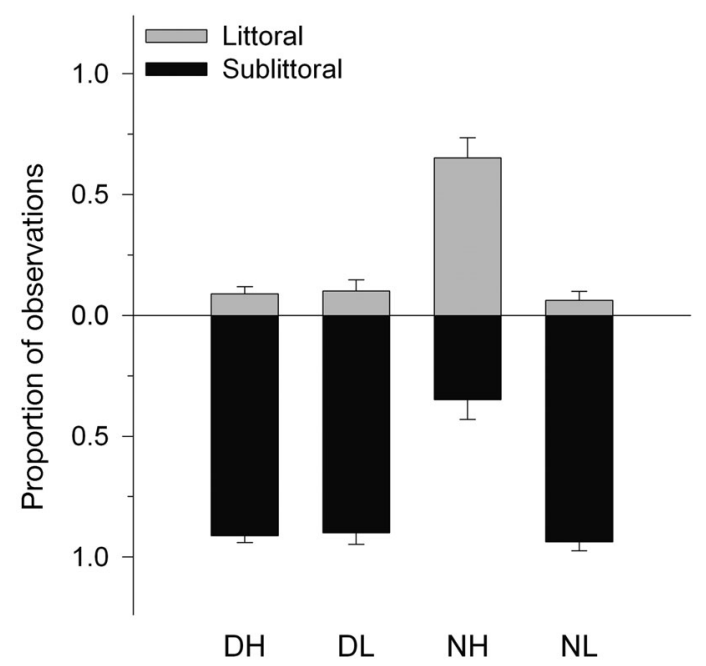

Fig. 9. Cancer magister. Daily mean ( $\pm 1 \mathrm{SE}$ ) proportions of crabs observed with acoustic telemetry in littoral or sublittoral habitats during each tidal period: daytime high (DH), daytime low (DL), nighttime high $(\mathrm{NH})$, and nighttime low (NL)

that dramatically alters the perception of the crab as a primarily sublittoral species in estuarine nurseries.

In NE Pacific estuaries, subadult Cancer magister are most abundant in secondary side channels (Rooper et al. 2002) that are surrounded by extensive littoral habitats. Results of a bioenergetics model have sug-

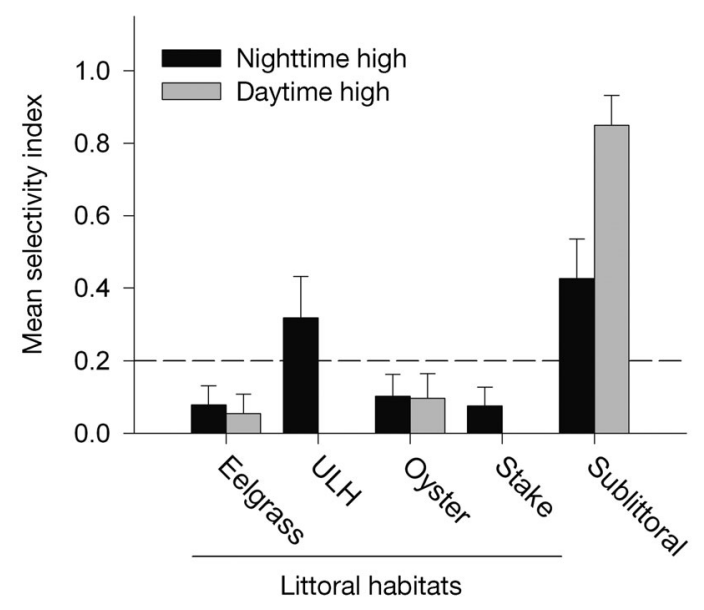

Fig. 10. Cancer magister. Mean selectivity indices (+1 SE) for each littoral habitat for nighttime and daytime high tides. Dashed line indicates random selectivity $(0.2)$; values above and below the line indicate preference and avoidance, respectively

gested that littoral prey consumed during intertidal forays provide a critical subsidy for populations of C. magister. These are estimated to fulfill 80 to $90 \%$ of daily energetic demands, which cannot be satisfied in sublittoral channels, where prey biomass is too low to support crab production and agonistic interactions further reduce foraging time (Holsman et al. 2003). The results of the present study are consistent with model predictions, since both telemetry and underwater video observations showed that crabs regularly migrate into littoral habitats.

Intertidal migrations may allow crabs to increase foraging opportunities and decrease agonistic activity. Previous studies of estuarine systems have found that prey biomass is significantly greater in littoral areas than in sublittoral channels (See Table 1 in Gunderson et al. 1990), and migrating species are thought to benefit from increased foraging opportunities resulting from differences in prey abundance (e.g. Gibson 2003). Stevens et al. (1984) correlated the abundance of subadult Cancer magister with intertidal migrations of a common prey species, sand shrimp Crangon spp., and similarly during our underwater video observations we witnessed occasional predation events on juvenile English sole Parophrys vetulus that were migrating into littoral areas (K. K. Holsman pers. obs.). Ongoing work is examining the gut content and fullness of crabs migrating into and out of various littoral habitats to determine whether increased prey availability and biomass drive intertidal migrations by subadult C. magister; preliminary results indicate that gut fullness is greatest for crabs moving out of littoral habitats during ebb tides (K. K. Holsman unpubl. data). 
Additionally, subadult Cancer magister compete aggressively while foraging, and larger crabs often displace and occasionally injure smaller ones (P. S. McDonald pers. obs.). Sublittoral crowding and agonistic encounters may be reduced as crabs disperse into littoral habitats to feed. Kaiser et al. (1990) found that smaller Carcinus maenas forage in littoral habitats at high tide to avoid agonistic encounters, and subadult $C$. magister may similarly limit encounter time with conspecifics and reduce overall competition by migrating with the tide and increasing their foraging area. Further studies should explicitly examine apparent tidal patterns in the behavior of subadult C. magister, particularly in relation to prey availability and agonistic activity.

Our telemetry work shows that subadult Cancer magister activity may be influenced by circadian periodicity since, despite access at high tide, few tagged individuals moved into littoral areas during daylight hours. Instead, most crabs were relatively sedentary, but activity increased between dusk and dawn when crabs often migrated to littoral habitats or moved within sublittoral channels. Although we were unable to detect clear evidence of circadian rhythms in video observations, and neither of our trapping surveys explicitly compared day and night catches, diel patterns of movement have been observed in C. magister from Grays Harbor, Washington (Stevens et al. 1984). Many other crabs are known to have daily rhythms as well, and nocturnal peaks in activity are common in the Cancer clade as a whole (see review by Novak 2004).

Regardless of the purpose, movements into littoral habitats are assumed to confer an advantage to those individuals that migrate. However, the benefits may be offset if the energetic cost of migration is too high (Gibson 2003). We suggest that subadult Cancer magister may rely on tidal currents to facilitate intertidal migrations. There is a strong correlation between net movement of crabs and water velocity and direction in the 2003 video data, and recordings revealed that migrating crabs augment walking with swimming or passive gliding just above the substrate. These behaviors may also allow C. magister to access distant littoral areas more quickly. Considering that subadult crabs can only sustain moderate walking speeds $\left(3.5 \mathrm{~m} \mathrm{~min}^{-1}\right)$ for short periods of time (McMahon et al. 1979, DeWachter \& McMahon 1996), it is likely that the tagged crabs we observed traveling more than $600 \mathrm{~m}$ into littoral flats (1.2 $\mathrm{km}$ round-trip) utilized strong tidal currents to do so. During flood tides, tagged individuals often moved into littoral areas along one vector, and subsequently followed an inverse trajectory during the ebb tide to return to the same spot in a sublittoral channel. Conceivably, crabs use a combination of learned migratory paths and directional water movement to navigate in and out of littoral habitats; thus, migration patterns are likely influenced by the magnitude and duration of tidal events. The strong tidal currents associated with extreme spring tides may not only act as directional cues for migration, but may also facilitate the movement of crabs into littoral areas, and migrations may be more extensive in areas where currents are strongest.

In addition to the patterns of activity described above, subadult Cancer magister exhibit selective use of available habitats. In the present study, crabs utilized ULH more frequently and to a greater extent than highly structured littoral eelgrass or oyster areas, and this pattern was consistent across all 3 methods of observation. Habitat complexity strongly influences predator-prey dynamics by directly reducing predator foraging efficiency (Crowder \& Cooper 1982, Fernandez et al. 1993). In NE Pacific estuaries, highly structured on-bottom oyster culture and eelgrass provide important refugia for small prey (Thayer \& Phillips 1977, Iribarne et al. 1995, Dumbauld et al. 2000) since the increased physical relief of structurally complex areas results in lower predation rates. The cryptic nature of benthic organisms living in structured habitats likely increases search and handling time and lowers overall foraging efficiency of predators, such as subadult C. magister.

Structural complexity may also affect the foraging efficiency of predators by obstructing their movements. Vegetative structure has been shown to impede the movements of Callinectes sapidus migrating into littoral areas during flood tides (Kneib 1995), and patch size has been shown to impact abundance of prey by impeding predators (Eggleston et al. 1999, Hovel \& Lipcius 2001). Predation impacts are typically higher along the edges of eelgrass or oyster beds than within patch centers (Iribarne et al. 1995, Fagan et al. 1999), a pattern attributed to the inability of many predators to penetrate structured habitats. We observed similar patterns in the present study; traps set at the edge of eelgrass and oyster beds caught more Cancer magister than ones placed within the center. Furthermore, when crabs in our telemetry study occasionally penetrated eelgrass beds during high tides, they frequently could not be located at subsequent low tides, and may have been stranded when water receded. Stranding is particularly stressful for larger C. magister, which are more sensitive to temperature fluctuations than smaller juveniles (Gutermuth \& Armstrong 1989). We suggest that the risk of stranding during low tide coupled with reduced foraging efficiency in complex habitats likely deter most subadult $C$. magister from using eelgrass and oyster beds, despite the high density of potential prey species they support. 
Unstructured habitats dominate littoral areas of Willapa Bay and support known prey of Cancer magister (Gunderson et al. 1990, Ferraro \& Faith 2004). Prey species often occur at lower densities in ULH than other habitats (Ferraro \& Faith 2004), but increased accessibility may offset lower abundances. Subadult C. magister may also benefit from greater mobility in ULH than structurally complex habitats. Littoral prey species are not distributed evenly (e.g. Clark et al. 2000), and foraging success may be improved by increasing search efficiency over large areas. We observed tagged crabs returning to particular areas of ULH on successive tides, which suggests that once a patch is discovered it may be exploited repeatedly. Our results corroborate previous studies that implicate C. magister as an important predator in unstructured littoral areas (Fernandez et al. 1993, Yamada \& Boulding 1996, Fernandez 1999).

While on-bottom oyster culture is critical to youngof-the-year Cancer magister (Dumbauld et al. 1993, 2000, Fernandez et al. 1993), subadult crabs in our study utilized these areas far less frequently. This highlights an important ontogenetic shift in habitat use by $C$. magister, and may partially result from changes in foraging efficiency and physiology with ontogeny. However, interactions with a congener, C. productus, likely contribute as well. It seems that $C$. productus are resident within oyster beds of Willapa Bay; we never observed these crabs migrating in video recordings, and they were often found buried in littoral areas at low tide, especially in dense beds of mature oysters (K. K. Holsman pers. obs.). Adult C. productus are aggressive predators and competitors, known to capture and consume smaller crabs (Jensen 1995, Hunt \& Yamada 2003) and displace other decapods while foraging. The strong inverse relationship between catches of these species in the present study suggests that subadult $C$. magister avoid areas occupied by C. productus. Subadult crabs may reduce the risk of predation or injury by utilizing ULH, since large C. productus are found at relatively low densities outside structured habitats. Ongoing experiments will elucidate the nature of competitive interactions between these species and the potential for C. productus to exclude C. magister from oyster beds (K. K. Holsman unpubl. data).

The pattern of habitat use described above for Cancer magister highlights the importance of small differences in biotic and abiotic aspects of microhabitats, and implies that factors other than prey density strongly affect habitat use by a migrating predator. The present study also adds to an increasing body of literature that emphasizes the importance of biotic, physical, and chemical cues to patterns of predator movement (Micheli 1997, Finelli et al. 2000, Alofs \&
Polivka 2004). Powers \& Kittinger (2002) showed that flow dynamics strongly affect odor-mediated movements, and that the specific response of predators to changes in water velocity greatly impact predator-prey dynamics. Similarly, factors such as habitat fragmentation, physical structure, competition, and prey distribution strongly influence these interactions (Paine \& Levin 1981, Wootton et al. 1996, Eggleston et al. 1998). We have shown that tidal influence is also critical when examining the behavior of foraging predators. Incorporating these realized patterns of movement into models of habitat selection is necessary to clarify key mechanisms governing the structure of littoral communities in estuarine systems.

Our findings suggest that unstructured habitats may be the primary foraging ground for migrating crabs and are therefore critical to crab production in these systems. However, a variety of human activities, including ship-canal dredging, upstream sediment loading, mariculture practices, and pesticide use, are modifying littoral habitats at an increasing rate (Wainwright et al. 1992, Simenstad \& Fresh 1995, Feldman et al. 2000, Dumbauld et al. 2001). These perturbations threaten to impact populations of Cancer magister either directly, through mortality of crabs in littoral habitats during high tides, or indirectly, through changes in the abundance of littoral prey. Littoral areas are also affected by invasions of non-indigenous species. In recent years, smooth cordgrass Spartina alterniflora and Japanese eelgrass Zostera japonica have begun to colonize ULH in several estuaries of the NE Pacific (Posey 1988, Feist \& Simenstad 2000), and their impact on populations of $C$. magister is poorly understood. Widespread alteration of ULH may negatively impact overall production of C. magister, particularly in areas adjacent to subtidal channels. Considering the importance of estuarine populations to the stability of coastal C. magister fisheries (Armstrong et al. 2003), decisions affecting littoral habitats should be approached cautiously. Far less conservation effort and attention have been directed toward ULH, including mud and sandflats, than other critical estuarine habitats such as eelgrass beds, oyster reefs, or emergent marshes. Regional declines in C. magister populations may be related to widespread loss of ULH in historically productive estuaries such as San Francisco Bay, California. Future restoration and conservation efforts should consider the ecosystem value of ULH, which is essential to sustaining populations of $C$. magister and myriad other species in coastal estuaries.

Acknowledgements. Our appreciation goes to B. Dumbauld and J. Ruesink for their help with experimental design and site selection and we are grateful for the help of numerous Willapa Bay oyster growers who provided access to oyster 
culture beds. We are also deeply indebted to A. Admundsen, M. Henderson, E. Holsman, and B. Lee for their invaluable assistance in the field, and we thank R. Holsman and L. Holsman for their generous contribution of field equipment and supplies. The manuscript was greatly improved by comments from T. Essington and 3 anonymous reviewers. This paper is a result of research funded by the University of Washington School of Aquatic and Fishery Sciences and the National Oceanic and Atmospheric Administration Coastal Ocean Program under award \#NA96OP0238 to the University of Washington. Research conducted for this study was done in accordance with institutional, national and international guidelines concerning the use of animals in research and the sampling of endangered species.

\section{LITERATURE CITED}

Abello P, Reid DG, Naylor E (1991) Comparative locomotoractivity patterns in the portunid crabs Liocarcinus Holsatus and L. Depurator. J Mar Biol Assoc UK 71:1-10

Aebischer NJ, Robertson PA, Kenward RE (1993) Compositional analysis of habitat use from animal radio-tracking data. Ecology 74:1313-1325

Alofs KM, Polivka KM (2004) Microhabitat-scale influences of resources and refuge on habitat selection by an estuarine opportunist fish. Mar Ecol Prog Ser 271:297-306

Armstrong DA, Rooper C, Gunderson D (2003) Estuarine production of juvenile Dungeness crab (Cancer magister) and contribution to the Oregon-Washington coastal fishery. Estuaries 26:1174-1188

Arthur SM, Manly BFJ, McDonald LL, Garner GW (1996) Assessing habitat selection when availability changes. Ecology 77:215-227

Asson Batres MA (1986) The feeding behavior of the juvenile Dungeness crab, Cancer magister Dana, on the bivalve, Transennella tantilla (Gould), and a determination of its daily consumption rate. Calif Fish Game 72:144-152

Bertness MD (1981) Predation, physical stress, and the organization of a tropical rocky intertidal hermit crab community. Ecology 62:411-425

Boulding EG (1984) Crab-resistant features of shells of burrowing bivalves: decreasing vulnerability by increasing handling time. J Exp Mar Biol Ecol 76:201-223

Byers JE (2002) Physical habitat attribute mediates biotic resistance to non-indigenous species invasion. Oecologia 130:146-156

Chatterton TD, Williams BG (1994) Activity patterns of the New Zealand cancrid crab Cancer novaezelandiae (Jacquinot) in the field and laboratory. J Exp Mar Biol Ecol 178:261-274

Clark ME, Wolcott TG, Wolcott DL, Hines AH (2000) Foraging behavior of an estuarine predator, the blue crab Callinectes sapidus in a patchy environment. Ecography 23: 21-31

Connell JH (1961) The influence of interspecific competition and other factors on the distribution of the barnacle Chthamalus stellatus. Ecology 42:710-723

Connell JH (1970) A predator-prey system in marine intertidal region. 1. Balanus glandula and several predatory species of Thais. Ecol Monogr 40:49-78

Crowder LB, Cooper WE (1982) Habitat structural complexity and the interaction between bluegills and their prey. Ecology 63:1802-1813

Dare PJ, Edwards DB (1981) Underwater television observations on the intertidal movements of shore crabs, Carcinus maenas, across a mudflat. J Mar Biol Assoc UK 61:107-116
Dayton PK (1971) Competition, disturbance, and community organization: the provision and subsequent utilization of space in a rocky intertidal community. Ecol Monogr 41: 351-389

DeWachter B, McMahon BR (1996) Haemolymph flow distribution, cardiac performance and ventilation during moderate walking activity in Cancer magister (Dana) (Decapoda, Crustacea). J Exp Biol 199:627-633

Dumbauld BR, Armstrong DA, McDonald TL (1993) Use of oyster shell to enhance intertidal habitat and mitigate loss of Dungeness crab (Cancer magister) caused by dredging. Can J Fish Aquat Sci 50:381-390

Dumbauld BR, Visser EP, Armstrong DA, Cole Warner L, Feldman KL, Kauffman BE (2000) Use of oyster shell to create habitat for juvenile Dungeness crab in Washington coastal estuaries: status and prospects. J Shellfish Res 19: 379-386

Dumbauld BR, Brooks KM, Posey MH (2001) Response of an estuarine benthic community to application of the pesticide carbaryl and cultivation of pacific oysters (Crassostrea gigas) in Willapa Bay, Washington. Mar Pollut Bull 42:826-844

Eggleston DB, Armstrong DA (1995) Pre- and post-settlement determinants of estuarine Dungeness crab recruitment. Ecol Monogr 65:193-216

Eggleston DB, Etherington LL, Elis WE (1998) Organism response to habitat patchiness: species and habitatdependent recruitment of decapod crustaceans. J Exp Mar Biol Ecol 223:111-132

Eggleston DB, Elis WE, Etherington LL, Dahlgren CP, Posey $\mathrm{MH}$ (1999) Organism responses to habitat fragmentation and diversity: habitat colonization by estuarine macrofauna. J Exp Mar Biol Ecol 236:107-132

Fagan WE, Cantrell RS, Cosner C (1999) How habitat edges change species interactions. Am Nat 153:165-182

Feist BE, Simenstad CA (2000) Expansion rates and recruitment frequency of exotic smooth cordgrass, Spartina alterniflora (Loisel), colonizing unvegetated littoral flats in Willapa Bay, Washington. Estuaries 23:267-274

Feldman KL, Armstrong DA, Dumbauld BR, DeWitt TH, Doty DC (2000) Oysters, crabs, and burrowing shrimp: review of an environmental conflict over aquatic resources and pesticide use in Washington state's (USA) coastal estuaries. Estuaries 23:141-176

Fernandez M (1999) Cannibalism in Dungeness crab Cancer magister: effects of predator-prey size ratio, density, and habitat type. Mar Ecol Prog Ser 182:221-230

Fernandez M, Iribarne O, Armstrong D (1993) Habitat selection by young-of-the-year Dungeness crab Cancer magister and predation risk in intertidal habitats. Mar Ecol Prog Ser 92:171-177

Ferraro SP, Faith AC (2004) Optimal benthic macrofaunal sampling protocol for detecting differences among four habitats in Willapa Bay, Washington, USA. Estuaries 27: 1014-1025

Finelli CM, Pentcheff ND, Zimmer RK, Wethey DS (2000) Physical constraints on ecological processes: a field test of odor-mediated foraging. Ecology 81:784-797

Forward RB Jr, Tankersley RA, Welch JM (2003) Selective tidal-stream transport of the blue crab Callinectes sapidus: an overview. Bull Mar Sci 72:347-365

Foster BA (1971) On the determination of the upper limit of the intertidal distribution of barnacles (Crustacea: Cirripedia). J Anim Ecol 40:33-48

Freire J, Gonzalez Gurriaran E (1998) New approaches to the behaviuoral ecology of decapod crustaceans using telemetry and electronic tags. Hydrobiologia 371-372:123-132 
Gee JM, Warwick RM, Davey JT, George CL (1985) Field experiments on the role of epibenthic predators in determining prey densities in an estuarine mudflat. Estuar Coast Shelf Sci 21:429-448

Gibson RN (2003) Go with the flow: tidal migration in marine animals. Hydrobiologia 503:153-161

Gonzalez Gurriaran E, Freire J, Bernardez C (2002) Migratory patterns of female spider crabs Maja squinado detected using electronic tags and telemetry. J Crustac Biol 22: 91-97

Gunderson DR, Armstrong DA, Shi YB, McConnaughey RA (1990) Patterns of estuarine use by juvenile English sole Parophrys vetulus and Dungeness crab Cancer magister. Estuaries 13:59-71

Gutermuth FB, Armstrong DA (1989) Temperature-dependent metabolic response of juvenile Dungeness crab cancer magister Dana: Ecological implications for estuarine and coastal populations. J Exp Mar Biol 126:135-144

Hamilton PV (1976) Predation of Littorina irrorata Mollusca Gastropoda by Callinectes sapidus Crustacea Portunidae. Bull Mar Sci 26:403-409

Holsman KK, Armstrong DA, Beauchamp DA, Ruesink JL (2003) The necessity for intertidal foraging by estuarine populations of subadult Dungeness crab, Cancer magister: evidence from a bioenergetics model. Estuaries 26: 1155-1173

Hooge PN, Eichenlaub B (1997) Animal movement extension to arcview. Alaska Science Center, Biological Science Office, US Geological Survey, Anchorage, AK

Hooper RG (1986) A spring breeding migration of the snow crab Chionoecetes opilio into shallow water in Newfoundland Canada. Crustac Int J Crustac Res 50:257-264

Hovel KA, Lipcius RN (2001) Habitat fragmentation in a seagrass landscape: patch size and complexity control blue crab survival. Ecology 82:1814-1829

Hunt CE, Yamada SB (2003) Biotic resistance experienced by an invasive crustacean in a temperate estuary. Biol Invasions 5:33-43

Hunter E, Naylor E (1993) Intertidal migration by the shore crab Carcinus maenas. Mar Ecol Prog Ser 101:131-138

Iribarne O, Armstrong D, Fernandez M (1995) Environmental impact of intertidal juvenile Dungeness crab habitat enhancement: effects on bivalves and crab foraging rate. J Exp Mar Biol Ecol 192:173-194

Jensen GC (1995) Pacific coast crabs and shrimps. Sea Challengers, Monterey, CA

Kaiser MJ, Hughes RN, Reid DG (1990) Chelal morphometry, prey-size selection and aggressive competition in green and red forms of Carcinus maenas (L.). J Exp Mar Biol Ecol 140:121-134

Kneib RT (1995) Behaviour separates potential and realized effects of decapod crustaceans in salt marsh communities. J Exp Mar Biol Ecol 193:239-256

Manly BFJ, McDonald LL, Thomas DL (1993) Resource selection by animals: statistical design and analysis for field studies. Chapman \& Hall, London

McMahon BR, McDonald DG, Wood CM (1979) Ventilation, oxygen uptake and haemolymph oxygen transport, following enforced exhausting activity in the Dungeness crab Cancer magister. J Exp Biol 80:271-285

Micheli F (1997) Effects of experience on crab foraging in a mobile and a sedentary species. Anim Behav 53: 1149-1159

Moksnes PO (2002) The relative importance of habitat-specific settlement, predation and juvenile dispersal for distribution and abundance of young juvenile shore crabs Carcinus maenas L. J Exp Mar Biol Ecol 271:41-73
Naylor E (1962) Seasonal changes in a population of Carcinus maenas (L.) in the littoral zone. J Anim Ecol 31:601-609

Novak M (2004) Diurnal activity in a group of Gulf of Maine decapods. Crustaceana 77:603-620

Paine RT (1974) Intertidal community structure: experimental studies on the relationship between a dominant competitor and its principal predator. Oecologia 15:93-120

Paine RT, Levin SA (1981) Intertidal landscapes: disturbance and the dynamics of pattern. Ecol Monogr 51:145-178

Posey MH (1988) Community changes associated with the spread of an introduced seagrass, Zostera japonica. Ecology 69:974-983

Powers SP, Kittinger JN (2002) Hydrodynamic mediation of predator-prey interactions: differential patterns of prey susceptibility and predator success explained by variation in water flow. J Exp Mar Biol Ecol 273:171-187

Robles C, Sweetnam DA, Dittman D (1989) Diel variation of intertidal foraging by Cancer productus L. in British Columbia. J Nat Hist 23:1041-1049

Rooper CN, Armstrong DA, Gunderson DR (2002) Habitat use by juvenile Dungeness crabs in coastal nursery estuaries. In: Paul AJ, Dawe Earl G, Elner R, Jamieson Glen S and 5 others (eds) Crabs in cold water regions: biology, management, and economics. University of Alaska Sea Grant College Program, Fairbanks, AK, p 609-629

Rooper CN, Gunderson DR, Armstrong DA (2003) Patterns in use of estuarine habitat by juvenile English sole (Pleuronectes vetulus) in four Eastern North Pacific estuaries. Estuaries 26:1142-1154

Ruesink JL, Roegner GC, Dumbauld BR, Newton JA, Armstrong DA (2003) Contributions of coastal and watershed energy sources to secondary production in a Northeastern Pacific estuary. Estuaries 26:1079-1093

Simenstad CA, Fresh KL (1995) Influence of intertidal aquaculture on benthic communities in Pacific Northwest estuaries: scales of disturbance. Estuaries 18:43-70

Stevens BG, Armstrong DA, Hoeman JC (1984) Diel activity of an estuarine population of Dungeness crabs, Cancer magister, in relation to feeding and environmental factors. J Crustac Biol 4:390-403

Stone RP, O'Clair CE (2001) Seasonal movements and distribution of Dungeness crabs Cancer magister in a glacial southeastern Alaska estuary. Mar Ecol Prog Ser 214: 167-176

Swihart RK, Slade NA (1985) Testing for independence of observations in animal movements. Ecology 66:1176-1184

Thayer GW, Phillips RC (1977) Importance of eelgrass beds in Puget Sound. Mar Fish Rev 39

Vannini M, Ruwa RK (1994) Vertical migrations in the tree crab Sesarma leptosoma (Decapoda, Grapsidae). Mar Biol 118:271-278

Wainwright TC, Armstrong DA, Dinnel PA, Orensanz JM, McGraw KA (1992) Predicting effects of dredging on a crab population: an equivalent adult loss approach. Fish Bull 90:171-182

Wolcott TG (1995) New options in physiological and behavioural ecology through multichannel telemetry. J Exp Mar Biol Ecol 193:257-275

Wootton JT, Power ME, Paine RT, Pfister CA (1996) Effects of productivity, consumers, competitors, and El Nino events on food chain patterns in a rocky intertidal community. Proc Natl Acad Sci USA 93:13855-13858

Yamada SB, Boulding EG (1996) The role of highly mobile crab predators in the intertidal zonation of their gastropod prey. J Exp Mar Biol Ecol 204:59-83

Zar JH (1999) Biostatistical analysis. 4th edn. Prentice Hall, Upper Saddle River, NJ 